\title{
Hydroethanolic extract of Sida rhombifolia L. ameliorates scopolamine-induced cognitive dysfunction in rats
}

\author{
Laxmi A. Pattanashetti ${ }^{*}$, Basanagouda M. Patil ${ }^{1 *}$, Harsha V. Hegde ${ }^{2}$, Ranjit Kangle ${ }^{3}$ \\ ${ }^{1}$ Department of Pharmacology, KLE College of Pharmacy, Belagavi. A Constitute Unit of K.L.E Academy of Higher Education and Research, Belagavi, India. \\ ${ }^{2}$ Department of Ethnomedicine and Medicinal plant. ICMR- National Institute of Traditional Medicine.Belagavi, Karnataka, India. \\ ${ }^{3}$ Department of Pathology, Jawaharlal Nehru Medical College, Belagavi, India.
}

\begin{tabular}{l}
\hline ARTICLE INFO \\
\hline Received on: 03/12/2020 \\
Accepted on: $20 / 03 / 2021$ \\
Available online: $05 / 05 / 2021$ \\
\\
\hline Key words: \\
Sida rhombifolia \\
acetylcholinesterase, \\
oxidative stress, $\beta$ amyloid $_{1-42}$, \\
Alzheimer's disease.
\end{tabular}

\section{INTRODUCTION}

The most prevalent form of dementia is Alzheimer's disease (AD) which expresses the features of memory loss and behavioral disturbance (Smith, 2017). Aging, especially people aged 65 years and above are at the risk of various diseases including AD. Every year nearly 1,275 new cases per 10,000 individuals are diagnosed with AD (Querfurth and LaFerla, 2010), and this has become challenging to nursing care facilities and financial burden for care givers.

\section{${ }^{*}$ Corresponding Author}

Laxmi A. Pattanashetti, Department of Pharmacology, KLE College of Pharmacy, Belagavi. A Constitute Unit of K.L.E Academy of Higher Education and Research, Belagavi, India.

E-mail: pattanashetti.laxmi67@gmail.com

\section{and}

Basanagouda M. Patil,

Department of Pharmacology, KLE College of Pharmacy, Belagavi. A Constitute Unit of K.L.E Academy of Higher Education and Research, Belagavi, India.E-mail:drbmpatil@klepharm.edu

\begin{abstract}
zheimer's disease is a neurodegenerative condition that involves cholinergic neuronal dysfunction, oxidative stress, treatment of neuronal disorders. This study was designed to evaluate the effect of S. rhombifolia extract (SRE) on (S) induced amnesia in rats. Sida rhombifolia hydroethanolic extract (SRE) was subjected to in-vitro $400 \mathrm{mg} / \mathrm{kg}$ of SRE for 15 days. Antioxidant activity of SRE was demonstrated by decreasing DPPH and $\mathrm{H}_{2} \mathrm{O}_{2}$ levels. Treatment group rats reversed SCO induced amnesia by improvement in spatial memory, decreased transfer latency and increased step through latency significantly $(p<0.001)$ in behavior models such as Morris water maze, elevated us maze, and passive avoidance task, respectively. SRE administration decreased acetylcholinesterase enzyme, $\beta$ decreasing lipid peroxidase levels. Histopathological studies revealed mild neuronal damage in treatment groups as compared to SCO-induced rats and is validated its implication for the treatment of cognitive impairment.
\end{abstract}


sida. The various extracts of $S$. rhombifolia have been identified as an anti-inflammatory, anti-arthritic, and hepatoprotective (Subramanya et al., 2015). It is also reported as an antidiabetic and poses antioxidant property (Chaturvedi and Kwape, 2015).

Traditionally in India, the hot aqueous extracts of dried leaf and root of the $S$. rhombifolia are used as an aphrodisiac, tonic and is used to treat heart and nervous diseases (Girón et al., 1991).

However, there are limited scientific reports related to claim the effect of $S$. rhombifolia in the management of AD. Hence, this study was designed to evaluate the hydro-ethanolic extract of S. rhombifolia L. on scopolamine (SCO) induced amnesia in rats.

\section{MATERIALS AND METHODS}

\section{Reagents}

Quercetin, Donepezil Hydrochloride, Tris-HCl, 2,2-diphenyl-1-picrylhydrazyl (DPPH), $\mathrm{H}_{2} \mathrm{O}_{2}$, 5,5'-dithiobis-(2nitrobenzoic acid), AChE, Acetylthiocholine iodide was procured by Sigma Aldrich, St. Louis, MO. Gallic acid, Ethanol (Hi-media, Amritsar, India), SCO hydrobromide (Vital Laboratories; Vapi, India), potassium dihydrogen phosphate, disodium hydrogen phosphate (SD fine chem. Ltd, Chennai, India), Folin-coicalteau phenol reagent (Fisher scientific, Vantaa, Finland).

\section{Plant collection and authentication}

The $S$. rhombifolia L. the whole plant was collected from the botanical garden, Dharwad University of Karnataka, India. Authenticated by botanist Dr. Harsh V. Hegde (Scientist E) at Indian Council of Medical Research-NITM, Belagavi, India. A voucher specimen (RMRC-1399) was deposited at the herbarium of ICMR-NITM, Belagavi, India.

\section{Method of extraction}

The whole plant was washed thoroughly using water and dried at room temperature for 15 days. Using a mechanical blender, plant parts were powdered. The hydro-alcoholic extract was prepared by three-time maceration using ethanol-water (70:30) for 7 days; further Soxhlet extraction was carried out using ethanol $(95 \%)$ for $8-12$ hours. This method allows isolating desirable phytoconstituents. Then extract was cooled, concentrated by the evaporation. Both extracts were combined and stored in a refrigerator until further use (Khanal and Patil, 2020).

Water and alcohol soluble extractive values and, ash values of crude powder were determined to assess the purity, quality as well as to detect adulterations present if any (Kokate, 2017). The $S$. rhombifolia extract (SRE) was screened for phytoconstituents such as tannins, phenols, flavonoids, saponins, glycoside, alkaloids qualitatively (Oshadie et al., 2017).

\section{Total flavonoid content and phenolic content}

The flavonoid content of SRE was quantified and quercetin was used as a standard sample (McDonald et al., 2001). Phenolic compounds of SRE were tested by a spectrophotometric method using Folin-Ciocalteau Reagent (Pawar et al., 2016), and values were reported as mg/g Gallic Acid Equivalent (GAE).

\section{DPPH and $\mathrm{H}_{2} \mathrm{O}_{2}$ scavenging activity of SRE}

The anti-oxidant activity of SRE was determined by the DPPH scavenging assay method proposed by Teh et al. (2013), and the ability to eliminate hydrogen peroxide was determined by method Ruch et al. (1989). Ascorbic acid was used as standard drugs with three independent tests were carried out to assure the precision of results.

\section{In-vitro estimation of $\mathrm{AChE}$ inhibition}

Acetylcholinesterase activity of SRE by in vitro was measured by 96 well microplate assay using Ellman's method. Donepezil was used as a standard control.

Percentage of enzyme inhibited was reported in triplicates to calculate $\mathrm{IC}_{50}$ values by linear regression analysis (Dhanasekaran et al., 2015).

\section{In vivo experimental protocol}

\section{Ethical approval and experimental animals}

Ethical consent was approved from the Institutional Animal Ethical Committee from KLE College of Pharmacy, Belagavi, an in vivo analysis was carried out (KLECOP/CPCSEARes No.221/Po/Res/2000/CPCSEA, Res.25-13/10/2018). Rats were procured by CPCSEA-registered vendor in vivo Biosciences; Bangalore, India.

The healthy Wistar rats of either sex (18 months) weighing 180-280 g used for this study, under standard laboratory conditions rats were housed in cages by grouping them into six in each with the maintenance of natural light and dark condition. Acclimatization was made before the experiment begins. CPCSEA guidelines were followed for experimentation. Rats were fed with standard rat chow pellet and water ad libitum.

\section{Acute oral toxicity study}

Organization for Economic Co-operation and Development guidelines, 423 (OECD, 2002) was used to determine the safety and adverse effects of SRE to confirm safe doses for future study. The SRE $2,000 \mathrm{mg} / \mathrm{kg}$ orally administered in a single dose to the rats later observed for the next 14 days. After 14 days, there were no side effects, no mortality was observed. Based on the acute oral toxicity study, the geometrical series doses such as $1 / 10$ th $1 / 20$ th, and $1 / 40$ th doses were selected as testing doses.

\section{Preparation of test samples}

The SR extract was suspended in $0.5 \%$ Sodium carboxy methyl cellulose (CMC) before administration.

Study design

The experimental rats were randomly selected $(n=6)$ and divided them into six groups. Group I: Normal control (administered with normal saline, through i.p route); $\mathrm{SCO}(1 \mathrm{mg} / \mathrm{kg}$, i.p) was administered for 30 days to group II - VI to provoke cognitive impairment. Group III- Standard control (Donepezil 3mg/ kg, p.o); Group IV- SRE 100mg/kg; Group V- SRE 200mg/kg; Group VI- SRE $400 \mathrm{mg} / \mathrm{kg}$ were administered orally (test controls). The test doses of donepezil and SRE were given 30 min after SCO administration to rats from 16-30th day to intervene SCO-induced amnesia.

\section{Screening models for amnesia}

Morris water maze task

It has a circular pool filled with water (the white dye used to make it opaque), pool was divided into four equal 
quadrants. Platform immersed $2 \mathrm{~cm}$ below the base level $(10 \times$ $10 \mathrm{~cm}$ ) and kept at the center of the Q4 quadrant throughout the testing sessions.

Training trial

Each rat was put in the pool for the 60 seconds 1 day before the test; this free swim allowed the rat to become accustomed to the training setup. Suppose in the 120 seconds, the rat did not find the platform then it was manually guided to reach the platform and allowed to rest on the platform for the 30 seconds.

Acquisition trail

During each day of the study, starting location was randomized but stayed the same for all rats in each experiment. The rat was allowed in the pool with its head pointing toward the sidewall at each trial and given the 90 seconds to search for a hidden platform.

Retention trail

On day 30, the platform was taken away from the position, then time spent to the search of the missing platform is considered as a probe trial referred to as retrieval of memory (Morris, 1984).

\section{Elevated plus-maze}

It has four arms (two closed; two open arms where maze was elevated above the floor, and arms extended from a central platform).

\section{Acquisition trial}

On day 1 , at open arm; the rat was individually placed facing away from a central platform. The acquisition test was considered as transfer latency (TL) by the observation of time taken for the rat to move from open to the closed arm.

Retention of memory of rats was recorded on day 30 using TL and percentage time spends in the open arm (Jafarian et al., 2019).

\section{Passive avoidance test}

The apparatus has light and dark compartments in the shuttle box. To separate the compartment, guillotine door is adjusted either lowered or raised by the researcher. The floor has stainless steel rods in which the shock generator has connected dark compartments to transmit shock if the rat stepped into a dark area. Rats were habituated before trial later on day 1 they were placed in the light compartment; the guillotine door was opened for the rat to enter the dark compartment during which foot shock was given for 2 seconds, which is considered as step-through latency as acquisition test. Retention trial was recorded on day 30 including time spent in the dark compartment (Rezvani-Kamran et al., 2017).

\section{Collection of brain sample}

After screening behavioral models, animals were

sacrifced with a high dose of anesthetic ether. Brain samples were collected. Later biochemcal parameters such as AChE, $\beta$ amyloid $_{1-42}$, Glutathione (Reduced), and lipid peroxide enzyme levels were evaluated.

\section{Acetylcholinesterase inhibition assay}

The effect of SRE on AChE level can be detected by the inhibition of AChE level in the brain homogenate as explained by (Ellman et al., 1961). To quantify the rate of moles of substratehydrolyzed per min/grams of the tissue, absorbance was noted for 5 minutes at $412 \mathrm{~nm}$.

\section{AB1-42 content in brain tissue}

The assessment of rat $\beta$ amyloid $_{1-42}$ level was done by the Enzyme linked immunosorbent assay sandwich kit manual (Bioassay Technology Laboratory, China). Phosphate buffer (7.4) was used to homogenize the rat brain later, centrifuged at 5,000 $\mathrm{G}$ to collect supernatant which was used for the detection of $\beta$ amyloid $_{1-42}$. In parallel to the test samples, standard curve analysis was run. A multiscan spectrum spectrophotometer was utilized to check the absorbance at $450 \mathrm{~nm}$ OD (Thermo scientific, Multiscan GO); the readings were all carried out in triplicate (Malabade et al., 2015).

\section{Estimation of reduced glutathione}

Protocol (Ellman, 1959) was followed to estimate reduced glutathione in brain homogenate. The development of yellow color signifies glutathione (GSH) level which was expressed as $\mathrm{nm} / \mathrm{mg}$ protein.

\section{Lipid peroxidase assay}

The quantity of lipid peroxidation was measured according to the procedure followed by (Wills, 1966). Amount of malondialdehyde formed due to reaction with thiobarbituric acid. Absorbance was measured at $532 \mathrm{~nm}$ and expressed as $\mathrm{nm} / \mathrm{mg}$ protein

\section{Histopathological studies}

Rat brain tissue was collected from groups. Neutral buffered formalin $10 \%$ was used as a fixation reagent. Processing was done to obtain $4 \mu \mathrm{m}$ paraffin-embedded sections. Hematoxylin and Eosin staining reagent was used to examine under microscope $40 \times$ (Dhalwal et al., 2007).

\section{Statistical analysis}

Graph Pad Prism (version 5.0) was used for the data analysis; Analysis of variance and Tukey's post hoc test using were considered. Statistical difference was considered in terms of mean \pm standard errors of the mean (SEM) and $p<0.05$. To compute $\mathrm{IC}_{50}$ linear regression, the analysis was used.

\section{RESULTS}

The water and alcohol soluble extractive values of the crude powder were obtained as $3.8 \%$ and $1.5 \%$, respectively; total ash and acid insoluble ash value were found to $5.9 \%$ and $1.5 \%(W / W)$. The percentage yield of $S$. rhombifolia hydroethanolic extract was found to be $10.5 \%$ $W / W$. Phytoconstituents such as flavonoids, saponins, phenols, glycosides, tannins, and steroids were present. The quantitative analysis such as total flavonoid content, total phenolic content of SRE was found to be $87.78 \mathrm{ug} / \mathrm{ml}$ quercetin equivalent and $120.77 \mathrm{ug} / \mathrm{ml} \mathrm{GAE}$, respectively. 
The SRE inhibited DPPH at $\mathrm{IC}_{50}$ value of $175.74 \pm$ $10.51 \mu \mathrm{g} / \mathrm{ml}, p<0.01$ compared to ascorbic acid $35.73 \pm 0.85$ $\mu \mathrm{g} / \mathrm{ml}$. The $\mathrm{H}_{2} \mathrm{O}_{2}$ was inhibited at $\mathrm{IC}_{50}$ of $55.84 \pm 0.636 \mu \mathrm{g} / \mathrm{ml}$; $p<0.01$ when compared with ascorbic acid $47.81 \pm 0.66 \mu \mathrm{g} / \mathrm{ml}$.

\section{Effect of SRE on AChE inhibition by an in-vitro method}

The SRE showed to inhibit to inhibit $\mathrm{AChE}$ at $\mathrm{IC}_{50}$ of $53.11 \pm 2.39 \mu \mathrm{g} / \mathrm{ml}$ as compared to Donepezil $2.23 \pm 0.141 \mu \mathrm{g} / \mathrm{ml}$.

\section{Effect of SRE on spatial memory}

Figure 1 explains escape latency in seconds using the Morris Water Maze task to evaluate the restoration of spatial memory. Figure 1a shows training trials for 7 days before commencing treatment to rats, which expressed significantly decreased escape latency on day 7 as compared to day 1 of the training trial. Figure $1 \mathrm{~b}$ shows the donepezil and SRE treatment to respective groups intervened and showed a decrease in escape latency significantly compared to SCO-induced rats. Figure 1c shows that the SCO induction elevates escape latency significantly $(p<0.001)$ as compared to normal control, donepezil $(3 \mathrm{mg} / \mathrm{kg}$ ) and SRE at 100, 200, and $400 \mathrm{mg} / \mathrm{kg}$ treatment expressed decreased escape latency significantly $(p<0.001)$ when compared to rats exposed to SCO. Figure 1d represents a probe trial in which SCO-induced rats showed decreased time spent in the target quadrant as compared to normal control rats; while donepezil and SRE treated rats revealed increased time spent at the target quadrant significantly $p<0.001$ compared to $\mathrm{SCO}-$ induced rats. These observations indicate improvement in spatial memory.

\section{Effect of SRE on short term learning and memory}

Figure $2 \mathrm{a}$ shows the effect of SRE on the TL and Figure $2 \mathrm{~b}$ expresses percentage time spent in open arms following 5 minutes of exploration in an elevated plus-maze. The SCOinduced rats showed increased TL as compared to normal group rats. The donepezil (3 $\mathrm{mg} / \mathrm{kg})$ and SRE treatment at 100, 200, and $400 \mathrm{mg} / \mathrm{kg}$ doses have shown a marked reduction in TL in contrast to SCO-induced rats.

SCO induced rats markedly $(p<0.001)$ reduced the percentage of time spent by the rats in the open arms compared to normal control rats. However, donepezil, SRE at 100, 200, and $400 \mathrm{mg} / \mathrm{kg}$ showed increased time spent percentage in the open arms, respectively, in comparison to SCO-induced rats indicate retention of short term memory.
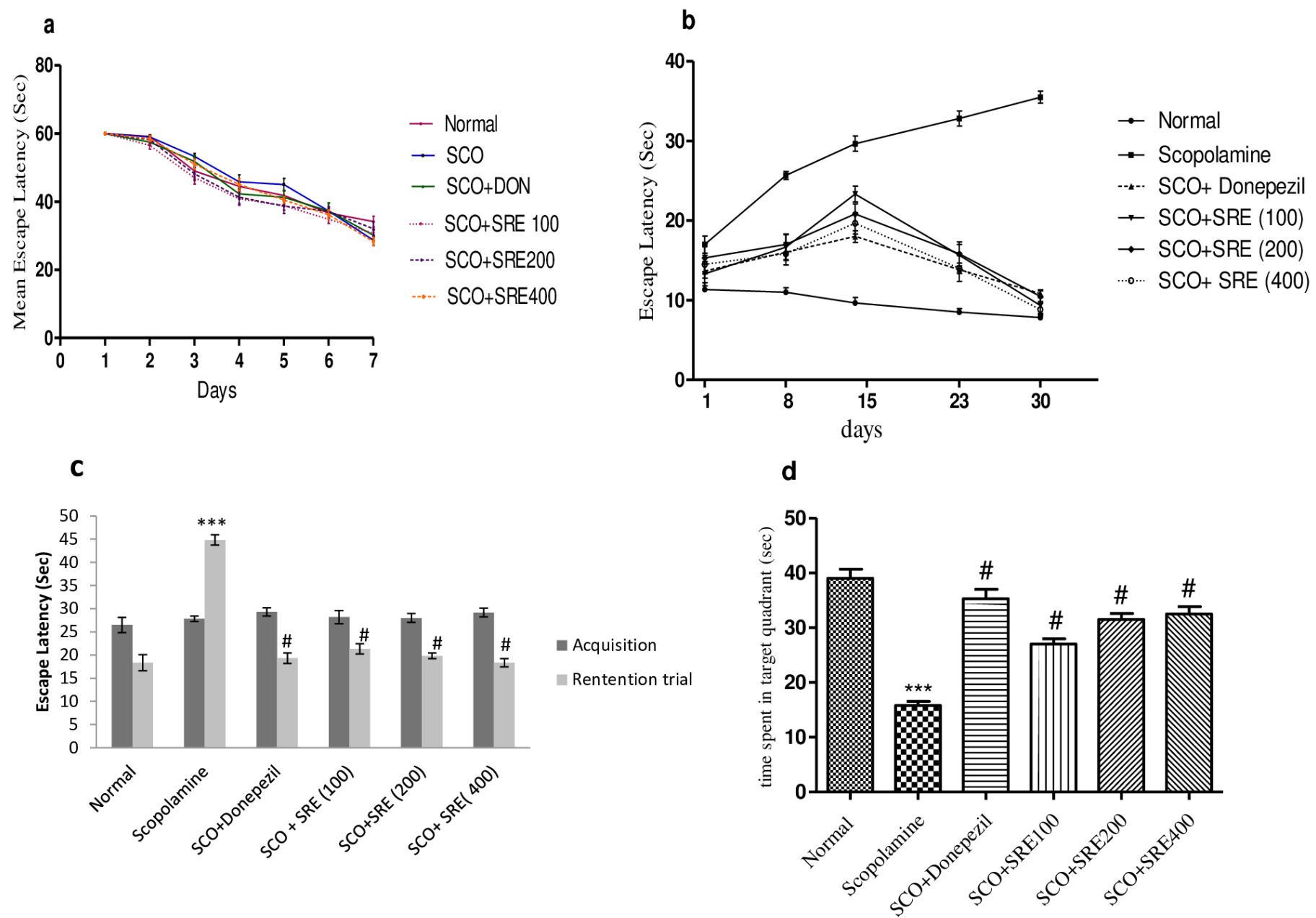

Figure 1. (a) Escape latency (sec) of rats during training trails. (b) Escape latency expressed by rots for every 7 days of treatment, (c) probe trial (time spent to reach target quadrant) compared to acquisition trial, (d) time spent in target quadrant by rats on probe trial: @ as compared to normal control group, ***compared to scopolamine control group. $p<0.001$ was considered as statistically significant. Data were represented as mean $\pm \operatorname{SEM}(n=6)$. 

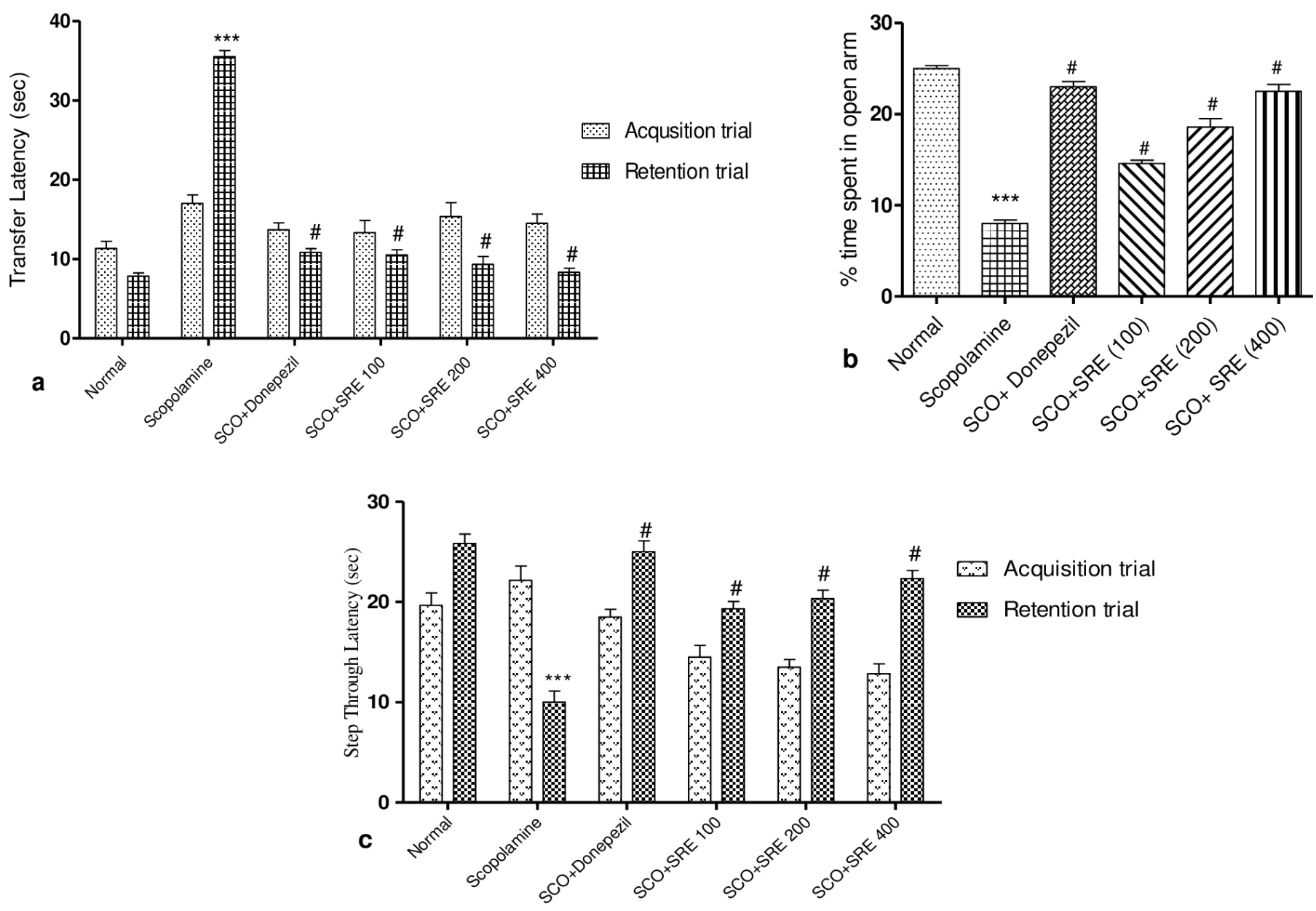

Figure 2. (a) Transfer latency (sec) of rats on elevated to plus maze, (b) percentage time spent by rats in open arm of EPM, (c) step through latency of rats in passive avoidant test: ***as compared to normal control group, \# compared to scopolamine control group. $p<0.001$ was considered as statistically significant. Data were represented as mean $\pm \operatorname{SEM}(n=6)$.

\section{Effect of SRE on fear aggravated related behavior}

Memory Retention trial on day 30 , the SCO administered rats showed significant $(p<0.001)$ decreased step-through latency which implies an increase in fear aggravated behavioral task. But, treatment groups viz, donepezil (3 mg/kg), SRE-100, 200, and 400 $\mathrm{mg} / \mathrm{kg}$ doses showed increased step-through latency indicates the improved non-declarative memory as shown in Figure 2c.

\section{Effect on AChE enzyme level in brain tissue}

The rats treated with SRE at 100, 200, $400 \mathrm{mg} / \mathrm{kg}$ significantly inhibited Acetylcholinesterase level by $(15.27 \pm 1.87$, $10.62 \pm 0.22,8.71 \pm 0.16 ; p<0.001)$, respectively, and Donepezil treated group also showed decreased AChE level $(8.09 \pm 0.75 ; p<$ $0.001)$ as compared to amnesia induced rats $(24.71 \pm 0.92)$. While SCO-induced rats increased AChE enzyme activity (24.71 \pm 0.92 ; $p<0.001)$ significantly as compared to normal rats $(7.26 \pm 0.45)$ as shown in Figure 3 a.

\section{$\boldsymbol{\beta}_{\text {-amyloid }}$ - $_{1-42}$ content in brain tissue}

In SCO-induced rats, amyloid $\beta_{1-42}$ was substantially increased in comparison to normal control $(655.7 \pm 35.68 \mathrm{pg} / \mathrm{ml}$; $p<0.001)$. Although a major significant decreased $\beta$-amyloid am $_{12}$ content was observed in rats treated with SRE, and donepezil $(p<$ 0.001 ) relative to SCO-induced rats, as shown in Figure $3 \mathrm{~b}$.

\section{Antioxidant activity of SRE}

Effect of SRE on malondialdehyde content

SCO-induced rats recorded notable changes in malondialdehyde levels $(39.53 \pm 3.05 ; p<0.001)$ relative to normal group rats $(12.8 \pm 2.86)$. Rats administered with SRE (14.96 \pm $3.16,13.89 \pm 3.05,12.29 \pm 2.41 ; p<0.001)$ and Donepezil $(11.75$ $\pm 1.97 ; p<0.001$ ) significantly reduced malondialdehyde (MDA) level which indicates decreased lipid peroxidation in rat brain as compared to SCO-induced rats as shown in Table 1.

\section{Effect of SRE on glutathione (reduced) level}

The SCO administered rats showed significantly decreased GSH level $(0.53 \pm 0.05 ; p<0.001)$ in comparison to normal control rats $(1.39 \pm 0.05)$. The rats treated with Donepezil $(1.23 \pm 0.11 ; p<0.001)$, SRE significantly increased $(1.07 \pm 0.12$, $1.20 \pm 0.07,1.31 \pm 0.05: p<0.001) \mathrm{GSH}$ levels as compared to SCO-induced rats as shown in Table 1. 

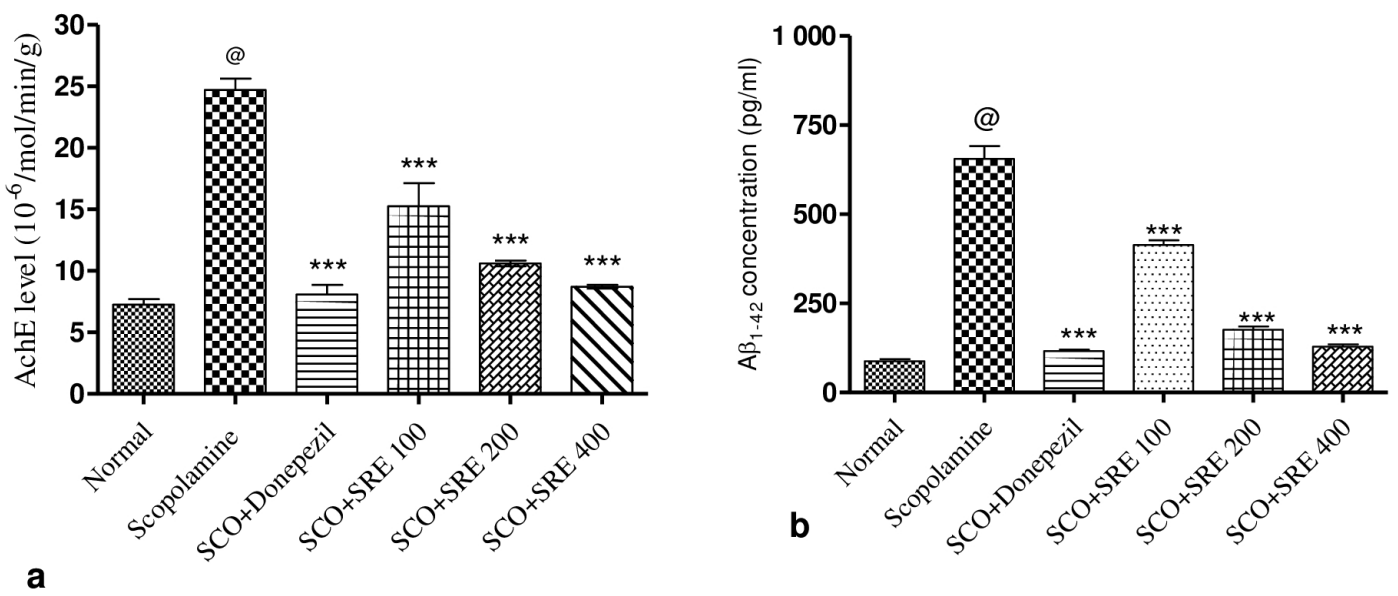

Figure 3. (a) AchE levels in rat brain homogenate, (b) $\mathrm{A} \beta_{1-42}$ concentration (pg/ml) in rat brain: @ as compared to normal control group, ***compared to scopolamine control group. $p<0.001$ was considered as statistically significant. Data were represented as mean $\pm \operatorname{SEM}(n=6)$.

Table 1. Anti-oxidant activity of SRE in rat brain homogenate.

\begin{tabular}{lcc}
\hline Group & $\begin{array}{c}\text { GSH reduced } \\
\text { (mmoles /mg of protein) }\end{array}$ & $\begin{array}{c}\text { LPO level (nmoles of } \\
\text { MDA/mg of protein) }\end{array}$ \\
\hline Normal control & $1.39 \pm 0.05$ & $12.82 \pm 2.86$ \\
$\mathrm{SCO}(1 \mathrm{mg} / \mathrm{kg})$ & $0.53 \pm 0.05^{\mathrm{a}}$ & $39.53 \pm 3.05^{\mathrm{a}}$ \\
$\mathrm{SCO}+$ Donepezil $(3 \mathrm{mg} / \mathrm{kg})$ & $1.23 \pm 0.11^{\mathrm{b}}$ & $11.75 \pm 1.97^{\mathrm{b}}$ \\
$\mathrm{SCO}+\mathrm{SRE}(100 \mathrm{mg} / \mathrm{kg})$ & $1.07 \pm 0.12^{\mathrm{b}}$ & $14.96 \pm 3.16^{\mathrm{b}}$ \\
$\mathrm{SCO}+\mathrm{SRE}(200 \mathrm{mg} / \mathrm{kg})$ & $1.20 \pm 0.07^{\mathrm{b}}$ & $13.89 \pm 3.05^{\mathrm{b}}$ \\
$\mathrm{SCO}+\mathrm{SRE}(400 \mathrm{mg} / \mathrm{kg})$ & $1.31 \pm 0.05^{\mathrm{b}}$ & $12.29 \pm 2.41^{\mathrm{b}}$ \\
\hline
\end{tabular}

Mean \pm SEM.

${ }^{\mathrm{a}}$ As compared to normal control.

${ }^{b} \mathrm{As}$ compared to $\mathrm{SCO}$ control group.

$p<0.001$ was considered as statistically significant.

\section{Histopathology of rat brain tissue}

SCO-induced rats reflected extreme neurodegeneration with perivascular edema, neuronophagia, and pyknotic nucleus in cortex and hippocampus regions of rat brain at $40 \times$ magnification. As observed in Figures 4 and 5, groups treated with donepezil and SRE protected neurons and demonstrated moderate congestion relative to the disease group.

\section{DISCUSSION}

The current study dealt to investigate $S$. rhombifolia hydroethanolic extract on SCO-induced amnesia by evaluating its effect on the short term, spatial memory, and fear aggravated behavior followed by estimation of $\mathrm{AChE}$ and antioxidants such as glutathione (reduced) and lipid peroxidation biomarkers using rat brain homogenate. Rat brain histopathology experiments have been performed on the cerebral cortex and hippocampus portions.

The most widely used free radical scavenging activity of potential extracts is tested by DPPH assay (Oroian and Escriche, 2015). The present study exhibits DPPH scavenging activity and this was as per Dhalwal et al. (2007) reports, who explained $S$. rhombifolia ethanolic extract free radical scavenging activity.

The SRE showed anti-oxidant potential by scavenging hydrogen peroxide; which is supported by a study observed by Chung et al. (1998) who noticed that the phenolic compounds found naturally in herbs are effective to converse deleterious effects of reactive oxygen species.

This research strongly directs us to assess the actions of S. rhombifolia in SCO-induced amnesic rats because an in vitro study reported that $S$. rhombifolia could inhibit AChE. These findings were correlated with previous reports (Mah et al., 2017).

Memory loss is a common characteristic of the elderly population; to reflect this disease, aged animals may be used as a natural dementia model that has been shown to develop neuropathology, oxidative stress accompanied by memory failure similarly found in patients affected with AD (Li et al., 2016).

SCO has been chosen as an amnesia-causing agent in current research because according to previous studies, SCO injection increases the function of $\mathrm{AChE}$, which metabolizes a significant amount of ACh synapses supply, indicates cognitive imbalance. Repeated dose administration of SCO aggravates the disorder (Rahimzadegan and Soodi, 2018; Soodi et al., 2014).

Spatial memory and learning are essential for identifying changes in the neuronal cholinergic system, which is well recognized by tasks such as the Morris water maze. Rats induced by SCO showed reduced time spent in the target quadrant in the present study, which was similarly observed in previous reports (Kaur and Mehan, 2015). Meanwhile rats treated with donepezil and SRE at 100, 200, $400 \mathrm{mg} / \mathrm{kg}$ increase time spent in target quadrant expressively; thus, attenuated behavioral changes caused by SCO.

SCO administered through the i.p. route in single or repeated doses can cause fear, anxiety, and depression-like behavior in rats and this can be prominently predicted by elevated plus-maze test (Aydin et al., 2016). However, rats treated with Donepezil, $S$. rhombifolia at selected therapeutic doses showed decreased TL and increased percentage time spent in the open arm; this served as improvement in exteroceptive learning and memory.

The treatment groups showed increased step-through latency significantly with less time spent at dark compartment as a compartment to SCO-induced rats. Reports were consistent with (Khurana et al., 2017) which explains increased step-through latency in passive avoidance tests and showed nootropic activity Sida species (S. cordifolia). 

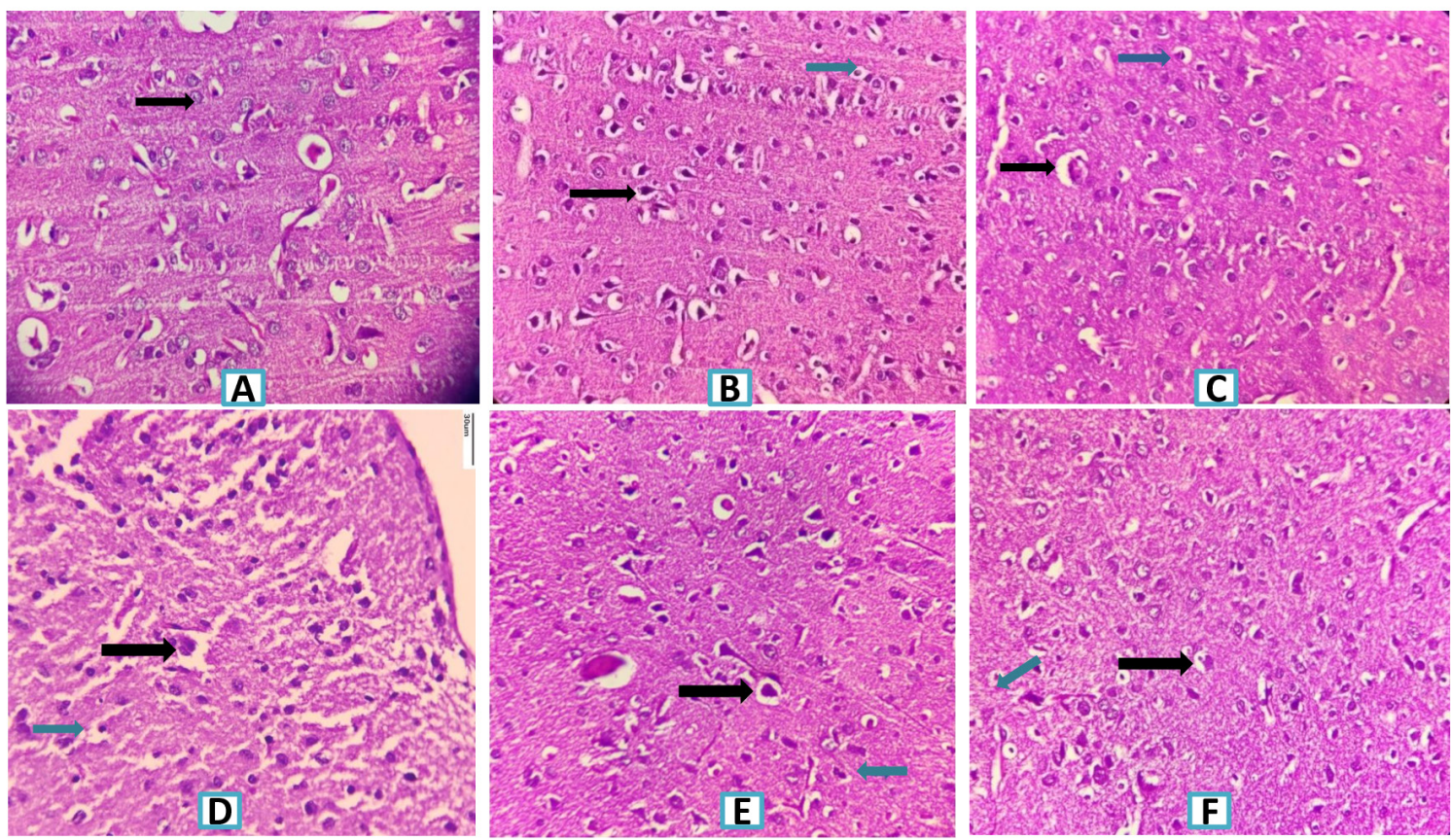

Figure 4. Histopathology of rat brain (Cerebral Cortex section) with H\&E $\times 400$. (A) Normal control group showing normal histological finding (Black arrow-normal

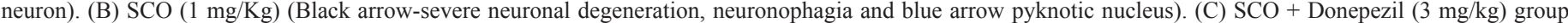
showing minimal neuronal degeneration. (Black arrow-mild congestion, blue arrow minimal neurodegeneration). (D) SCO $+\mathrm{SRE}(100 \mathrm{mg} / \mathrm{kg}$ ) group showing moderate neuronal degeneration with neurophagia with congestion of blood vessels. (Black arrow moderate edema and blue arrow shows moderate neurodegeneration). (E) $\mathrm{SCO}+\mathrm{SRE}(200 \mathrm{mg} / \mathrm{kg})$ group showing neuronal degeneration (Black arrow-mild newonal degeneration, blue arrow shows mild neurodegeneration). (F) SCO + SRE $(400 \mathrm{mg} / \mathrm{kg})$ group (Black arrow shows mild congestion and blue arrow shows mild neurodegeneration). *SRE = Sida rhombifolia hydroethanolic extract; SCO = Scopolamine.
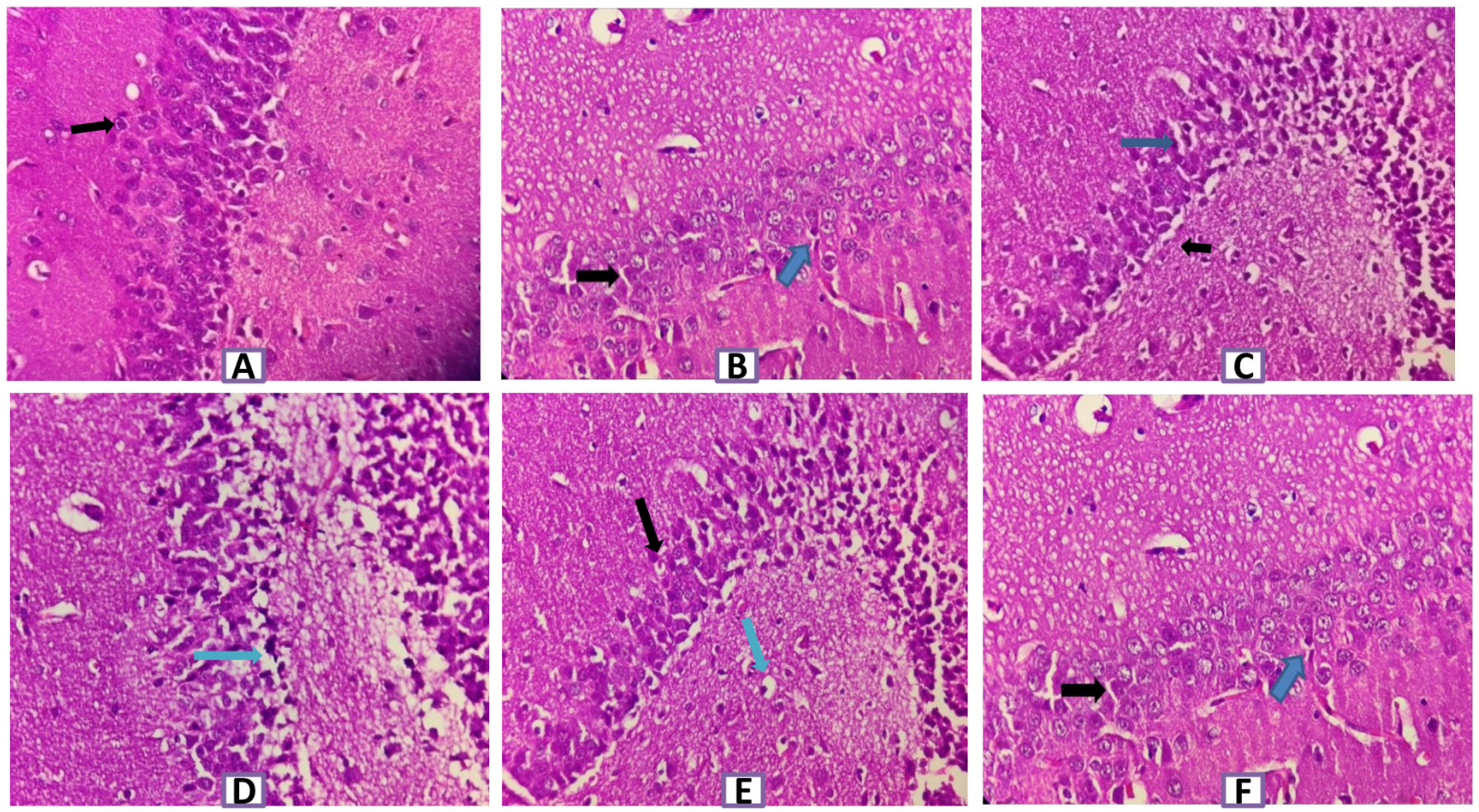

Figure 5. Histopathology of rat brain (Hippocampus section) with $\mathrm{H} \& \mathrm{E} \times 400$. (A) Normal control group showing normal healthy normochromic neurons with welloutlined cell bodies and absence of intercellular spaces (Black arrow-normal pyramidal cell). (B) SCO (1 mg/kg) induced group showing marked and severe neuronal degeneration with congested blood vesseIs, perivascular edema, neuronophagia, pyknotic cells and g1iosis (Black arrow- edema and blue arrow shows pyknotic cell). (C) SCO+ Donepezi $1(3 \mathrm{mg} / \mathrm{kg})+\mathrm{SCO}$ group showing mild neuronal degeneration \& neuronophagia (Black arrow-mild edema and blue arrow-few cells showing degeneration). (D) SCO+SRE $(100 \mathrm{mg} / \mathrm{kg}$ ) + SCO showing moderate neuronal degeneration with neuronophagia with congestion of blood vessels and edema (Blue arrow shows intercellular edema). (E) SCO + SRE $(200 \mathrm{mg} / \mathrm{kg})+\mathrm{SCO}$ showing mild perivascular edema with mild congestion and neuronal degeneration (Black arrow pyramidal cell degeneration and blue arrow-edema). (F) SCO+ SRE (400 mg/kg) + SCO showing mild perivascular edema and minimal pyknosis (Black arrow shows minimal pyknosis, Blue arrow shows mild edema). 
SCO-induced rats illustrated cholinergic neuronal damage by increasing $\mathrm{AChE}$ level in rat brain homogenate sample which is a sign of cognitive imbalance. On the contrary, rats administered with donepezil and SRE at concomitant doses showed improvement with the restoration of learning and memory by blocking the action of AChE and modulating the availability of ACh for synaptic transmission.

In the brain tissue aggregation of $\beta$ amyloid protein, especially $\beta$ amyloid $_{1-42}$ plaque deposition in extracellular space is a characteristic feature considered as a biomarker in cognitive dysfunction (Pattanashetti et al., 2017). The administration of SRE to the rats showed a marked reduction of $\beta$-amyloid ${ }_{1-42}$, which could interferes with aggregation process of beta-amyloid ${ }_{1-42}$ and protects neurons from damage.

The current study attempted to examine the influence of SRE on reduced GSH levels, which showed increased levels of reduced glutathione and the results were correlated with the previous study on antioxidant properties of $S$. rhombifolia root and stem extract (Narendhirakannan and Limmy, 2012). A significant increase in lipid peroxidation is measured by MDA levels which are considered as an index of oxidative stress. The activity of SRE resulted in decreasing the lipid peroxidation this was expressed by a decreased level of MDA and correlated with the study that expressed that $S$. rhombifolia root extract acts as a natural antioxidant estimated in rat brain homogenate (Bihaqi et al., 2011; Dhalwal et al., 2007).

Sections of the hippocampus; Cornuammonis (CA field), dentate, subicular complex are anatomical regions of the medial temporal lobe and these play an important role in mammalian memory (Squire, 1992). Histopathological rat brain studies showed that neuronal damage, neural fibrillary tangles hippocampal edema, and pyknotic cells were shown in the SCOinduced group, whereas groups treated with donepezil and SRE showed mild neuronal damage compared to SCO-induced damage.

Earlier scientific reports do confirm the presence of phytoconstituents of plant extract such as Phenolic compounds, flavonoids, alkaloids, $\quad \beta$-phenylethylamines, chlorophyll derivatives, steroids phenolic compounds, and these could contribute to cholinesterase enzyme inhibition and improve cognition (Babu et al., 2013; Chaves et al., 2017).

Genus Sida L. revealed its traditional claim for prevention and treatment of neurological disorder in which S. rhombifolia had given attention due to phytoconstituents like flavonoids, alkaloids, other phenolics, and ecdysteroids available in extracts (Dinda et al., 2015). Furthermore, on these presumed reports we planned to explore the possibility of SRE to restore memory and improve learning which was confirmed through decreased AChE; in turn, increases ACh availability at synapse and anti-oxidants present in SRE to combat oxidative stress produced by free radicals. These mechanisms were reported from improvement in spatial, short term memory with a decrease in fear aggravated behavior in rats.

\section{CONCLUSION}

The present study confirms the anti-amnesic activity of $S$. rhombifolia hydro-ethanolic extract through the mechanism of AChE inhibition and antioxidant pathways in SCO-induced rats. This supports the therapeutic value of herbal medicine to enhance memory in $\mathrm{AD}$, yet clinical applications are to be explored.

\section{AUTHOR CONTRIBUTIONS}

All authors made substantial contributions to conception and design, acquisition of data, or analysis and interpretation of data; took part in drafting the article or revising it critically for important intellectual content; agreed to submit to the current journal; gave final approval of the version to be published; and agree to be accountable for all aspects of the work. All the authors are eligible to be an author as per the international committee of medical journal editors (ICMJE) requirements/guidelines.

\section{FUNDING}

There is no funding to report.

\section{CONFLICTS OF INTEREST}

The authors report no financial or any other conflicts of interest in this work.

\section{ETHICAL APPROVALS}

Study protocol was approved from the Institutional Animal Ethical Committee from KLE College of Pharmacy, Belagavi, an in vivo analysis was carried out (KLECOP/CPCSEARes No.221/Po/Res/2000/CPCSEA, Res.25-13/10/2018).

\section{PUBLISHER'S NOTE}

This journal remains neutral with regard to jurisdictional claims in published institutional affiliation.

\section{REFERENCES}

Anand R, Gill KD, Mahdi AA. Therapeutics of Alzheimer's disease: past, present, and future. Neuropharmacology, 2014; 76(Part A): 27-50; doi:10.1016/j.neuropharm.2013.07.004

Aydin E, Hritcu L, Dogan G, Hayta S, Bagci E. The effects of inhaled pimpinellaperegrina essential oil on scopolamine-induced memory impairment, anxiety, and depression in laboratory rats. Mol Neurobiol, 2016; 53(9):6557-67; doi:10.1007/s12035-016-9693-9

Babu PVA, Liu D, Gilbert ER. Recent advances in understanding the anti-diabetic actions of dietary flavonoids. J Nutr Biochem, 2013; 24(11):1777-89; doi:10.1016/j.jnutbio.2013.06.003

Bihaqi SW, Singh AP, Tiwari M. In vivo investigation of the neuroprotective property of convolvulus pluricaulis in scopolamineinduced cognitive impairments in Wistar rats. Indian J Pharmacol, 2011; 43(5):520-5; doi:10.4103/0253-7613.84958

Chaturvedi P, Kwape TE. Attenuation of diabetic conditions by Sida rhombifolia in moderately diabetic rats and inability to produce similar effects in severely diabetic in rats. J Pharmacopuncture, 2015; 18(4):12-9; doi:10.3831/kpi.2015.18.032

Chaves OS, Teles YCF, De Oliveira Monteiro MM, das Graças Mendes Junior L, de Fátima Agra M, de Andrade Braga V, Silva TMS, de Fátima Vanderlei de Souza M. Alkaloids and phenolic compounds from Sida rhombifolia L. (Malvaceae) and vasorelaxant activity of two indoquinoline alkaloids. Molecules. 2017; 22(1):94; doi:10.3390/molecules22010094

Chung KT, Wong TY, Wei CI, Huang YW, Lin Y. Tannins and human health: a review. Crit Rev Food Sci Nutr, 1998; 38(6):421-64; doi:10.1080/10408699891274273

Citron M. Alzheimer's disease: strategies for disease modification. Nat Rev Drug Discov, 2010; 9(5):387-98; doi:10.1038/ $\operatorname{nrd} 2896$

Dhalwal K, Deshpande YS, Purohit AP. Evaluation of in vitro antioxidant activity of Sida rhombifolia (L.)Ssp. retusa (L.). J Med Food, 2007; 10(4):683-8; doi:10.1089/jmf.2006.129

Dhanasekaran S, Perumal P, Palayan M. In-vitro screening for acetylcholinesterase enzyme inhibition potential and antioxidant activity of 
extracts of ipomoea aquatic forsk: therapeutic lead for Alzheimer's disease. J Appl Pharm Sci, 2015; 5(2):12-6.

Dinda B, Das N, Dinda S, Dinda M, Sarma IS. The genus Sida L. - a traditional medicine: tt's ethnopharmacological, phytochemical and pharmacological data for commercial exploitation in herbal drugs industry. J Ethnopharmacol, 2015; 176:135-76.

Eckert GP. Traditional used plants against cognitive decline and Alzheimer disease. Front Pharmacol, 2010; 1:138; doi:10.3389/ fphar.2010.00138

Ellman GL. Tissue sulfhydryl groups. Arch Biochem Biophys, 1959; 82(1):70-7; doi:10.1016/0003-9861(59)90090-6

Ellman GL, Courtney KD, Andres V, Featherstone RM. A new and rapid colorimetric determination of acetylcholinesterase activity. Biochem Pharmacol, 1961; 7(2):88-90; doi:10.1016/0006-2952(61)90145-9

Girón LM, Freire V, Alonzo A, Cáceres A. Ethnobotanical survey of the medicinal flora used by the Caribs of Guatemala. J Ethnopharmacol, 1991; 34(2-3):173-87; doi:10.1016/0378-8741(91)90035-C

Jafarian S, Ling KH, Hassan Z, Perimal-Lewis L, Sulaiman MR, Perimal EK. Effect of zerumbone on scopolamine-induced memory impairment and anxiety-like behaviours in rats. Alzheimer's Dement Transl Res Clin Interv, 2019; 5:637-43.

Kaur, R., Mehan S, Khanna D, Kalra S. Ameliorative treatment with ellagic acid in scopolamine induced Alzheimer's type memory and cognitive dysfunctions in rats. Austin J Clin Neurol. 2015; 2(6):1053.

Khanal P, Patil BM. $\alpha$-Glucosidase inhibitors from Durantarepens modulate p53 signaling pathway in diabetes mellitus. Adv Tradit Med, 2020; 20:427-38; doi:10.1007/s13596-020-00426-w

Khurana N, Sharma N, Patil S, Gajbhiye A. Evaluation of nootropic activity of sidacordifolia in mice. Int J Green Pharm, 2017; 11(3):S417-22.

Kokate CK. Practical pharmacognosy. 53rd edition, Vallabh Prakashan Publication, New Delhi, India, pp 7.19-7.25, 2017.

Li X, Bao X, Wang R. Experimental models of alzheimer's disease for deciphering the pathogenesis and therapeutic screening (review). Int J Mol Med, 2016; 37(2):271-83.

Mah SH, Teh SS, Ee GCL. Anti-inflammatory, anti-cholinergic and cytotoxic effects of Sida rhombifolia. Pharm Biol, 2017; 55(1):920-8; doi:10.1080/13880209.2017.1285322

Malabade R, Ashok T. Cassia tora a potential cognition enhancer in rats with experimentally induced amnesia. J Young Pharm, 2015; 7(4):455-61; doi:10.5530/jyp.2015.4s.7

McDonald S, Prenzler PD, Antolovich M, Robards K. Phenolic content and antioxidant activity of olive extracts. Food Chem, 2001; 73(1):73-84; doi:10.1016/S0308-8146(00)00288-0

Morris R. Developments of a water-maze procedure for studying spatial learning in the rat. J Neurosci Methods, 1984; 11:47-60.

Narendhirakannan RT, Limmy TP. Anti-inflammatory and antioxidant properties of Sida rhombifolia stems and roots in adjuvant induced arthritic rats. Immunopharmacol Immunotoxicol, 2012; 34(2):326-36; doi: 10.3109/08923973.2011.605142

OECD. Test No. 423: acute oral toxicity - acute toxic class method. OECD Guidel Test Chem, 2002; 4:1-14. doi:10.1787/9789264071001- en

Oroian M, Escriche I. Antioxidants: characterization, natural sources, extraction and analysis. Food Res Int, 2015; 74:10-36.

Oshadie G, Silva D, Abeysundara AT, Minoli M, Aponso W. Extraction methods, qualitative and quantitative techniques for screening of phytochemicals from plants. Am J Essent Oils Nat Prod, 2017; 5(2):29-32.
Pattanashetti LA, Taranalli AD, Parvatrao V, Malabade RH, Kumar D. Evaluation of neuroprotective effect of quercetin with donepezil in scopolamine-induced amnesia in rats. Indian J Pharmacol, 2017; 49(1):60-4; doi:10.4103/0253-7613.201016

Pawar RS, Kumar S, Toppo FA, PK L, Suryavanshi P. Sida cordifolia Linn. accelerates wound healing process in type 2 diabetic rats. J Acute Med, 2016; 6(4):82-9; doi:10.1016/j.jacme.2016.08.004

Querfurth HW, LaFerla FM. Alzheimer's disease. N Engl J Med, $2010 ; 362: 329-44$

Rahimzadegan M, Soodi M. Comparison of memory impairment and oxidative stress following single or repeated doses administration of scopolamine in rat hippocampus. Basic Clin Neurosci, 2018; 9(1):5-14; doi:10.29252/nirp.ben.9.1.5

Rezvani-Kamran A, Salehi I, Shahidi S, Zarei M, Moradkhan S, Komaki A. Effects of the hydroalcoholic extract of Rosa damascena on learning and memory in male rats consuming a high-fat diet. Pharm Biol, 2017; 55(1):2065-73; doi:10.1080/13880209.2017.1362010

Ruch RJ, Cheng SJ, Klaunig JE. Prevention of cytotoxicity and inhibition of intercellular communication by antioxidant catechins isolated from chinese green tea. Carcinogenesis, 1989; 10(6):1003-8; doi:10.1093/ carcin/10.6.1003

Smith M. Genetics of Alzheimer's disease. Dementia, 2017; 23(4):519-27; doi:10.1201/9781315381572.

Soodi M, Naghdi N, Hajimehdipoor H, Choopani S, Sahraei E. Memory-improving activity of Melissa officinalis extract in naïve and scopolamine-treated rats. Res Pharm Sci, 2014; 9(2):107-14.

Squire LR. Memory and the hippocampus: a synthesis from findings with rats, monkeys, and humans. Psychol Rev, 1992; 99(2):195231; doi:10.1037/0033-295X.99.2.195

Subramanya MD, Pai SR, Upadhya V, Ankad GM, Bhagwat SS, Hegde HV. Total polyphenolic contents and in vitro antioxidant properties of eight Sida species from Western Ghats, India. J Ayurveda Integr Med, 2015; 6(1):24-8; doi:10.4103/0975-9476.146544.

Teh SS, Ee GCL, Mah SH, Yong YK, Lim YM, Rahmani M, Ahmad Z. In vitro cytotoxic, antioxidant, and antimicrobial activities of Mesua beccariana (Baill.) Kosterm., Mesua ferrea Linn., and Mesua congestiflora extracts. Biomed Res Int, 2013; 2013:1-10. doi:10.1155/2013/517072

Trikamji Y. Vatavyadhichikitsa: ayurvedadipika of chakrapanidatta on charakasamhita of agnivesa, In Charaka and Dridhabala Chikitsasthana. 1st edition, Varanasi, India: Chaukhambha Prakashan,pp 623,1984

Wills ED. Mechanisms of lipid peroxide formation in anima tissues. Biochem J, 1966; 99(3):667-76; doi:10.1042/bj0990667.

\section{How to cite this article:}

Pattanashetti LA, Patil BM, Hegde HV, Kangle R. Hydroethanolic extract of Sida rhombifolia L. ameliorates scopolamine-induced cognitive dysfunction in rats. J Appl Pharm Sci, 2021; 11(05):118-126. 